\title{
PRÁTICAS CORPORAIS MEDICALIZANTES: DIAGNOSTICANDO A REVISTA VIDA SIMPLES
}

\author{
MEDICALIZED BODY PRACTICES: DIAGNOSING VIDA SIMPLES MAGAZINE
}

PRÁCTICAS CORPORALES MEDICALIZANTES: DIAGNOSTICANDO A LA REVISTA VIDA SIMPLE

George Saliba Manske*, Thaís Silveira Barcelos**

\begin{abstract}
Palavras-chave Estilo de vida. Comportamento saudável. Artigo de revista.

Resumo: Esta pesquisa teve como objetivo analisar as práticas corporais descritas nas edições impressas da revista Vida Simples ao longo de 2014. Foram analisadas quatorze edições desta revista a partir dos conceitos de medicalização e de políticas da própria vida, desde suas inserções no campo dos Estudos Culturais. Constatou-se que as revistas analisadas apresentam as práticas corporais com significados vinculados a uma vida simples saudável, permeadas por discursos de ordem biomédica. Discutiramse, também, essas práticas a partir da noção de políticas da vitalidade e percebeu-se, no entanto, que tal noção não pôde ser diretamente vinculada às práticas descritas na revista.
\end{abstract}

Keywords

Life style.

Health behavior. Journal article.

Palabras clave Estilo de vida. Comportamiento saludable. Artículo de revista.

Abstract: This research aimed at analyzing body practices described in the printed editions of Vida Simples magazine in 2014. Fourteen editions were analyzed under the concepts of medicalization and policies of life itself, from their place in Cultural Studies. The magazines analyzed were found to include body practices with meanings linked to a healthy simple life, permeated by biomedical discourses. Those practices were also discussed under the notion of vitality policies, but that notion could not be directly linked to the practices described in the magazine.

Resumen: Esta investigación tuvo como objetivo analizar las prácticas corporales descritas en las ediciones impresas de la revista Vida Simple durante el año 2014. Catorce ediciones de la revista se analizaron desde los conceptos de la medicalización y de políticas de la propia vida, en su inserción en el campo de los Estudios Culturales. Se encontró que las revistas analizadas presentan las prácticas corporales con significados vinculados a una vida simple y saludable, impregnados por los discursos biomédicos. Se discuten, también, estas prácticas a partir de la noción de políticas de la vitalidad y se observó, sin embargo, que tal noción no puede ser directamente vinculada a las prácticas descritas en la revista.
* Universidade do Vale do Itajaí (UNIVALI). Itajaí, SC, Brasil. E-mail: gsmanske@yahoo.com.br

**Universidade do Vale do Itajaí (UNIVALI). Itajaí, SC, Brasil. E-mail: barcelos_sthais@yahoo.com.br

Recebido em: 15-04-2015 Aprovado em: 06-09-2015 (c) (i) () Licence 


\section{TER UMA VIDA SIMPLES COMPRANDO UMA VIDA SIMPLES}

Pode parecer incoerente, mas a vida simples ${ }^{1}$ dos seres humanos é mais complexa do que se pensa. Por mais corriqueiro que possa parecer que seja - ou que sugiram que seja -, a vida simples é um tema amplo e altamente subjetivo, pois pensar, viver ou compreender a prática e o termo vida simples nos remete à inserção num determinado estilo de existência. Os sujeitos que aderem a esse modo de ser e de relacionar-se optam por uma maneira de viver que difere da vida urbana encontrada em nosso século. As questões de escolha deste modo de vida podem estar ligadas a um sem-número de aspectos, tais como espiritualidade, religião, saúde, qualidade de vida, família, amigos, meio ambiente, lazer, finanças, consumo e outros, os quais são amplamente apontados pela revista Vida Simples, da Editora Abril, que se propõe a discutir esses aspectos para melhor orientar seus leitores em suas escolhas diárias. Os adeptos deste norteador abrem mão voluntariamente do que entendem por supérfluo, e abraçam essencialmente as suas escolhas na busca de uma vida "mais descomplicada", o que significa fazer esforços e privações em busca deste ideal.

Talvez fosse um contrassenso pensar que este ideal de vida, baseado em escolhas que privilegiam os aspectos minimalistas para uma satisfação pessoal, que envolvem 0 entendimento e envolvimento num processo de viver da forma "mais simples" possível poderia estar interligado, diretamente, às questões medicalizantes da vida. Porém, ao compreendermos a medicalização como um processo no qual o modo de vida dos homens é apropriado pela medicina, interferindo na construção de conceitos, regras, norma, moral, costumes e comportamentos sociais (FOUCAULT, 1988, 1997b, GAUDENZI; ORTEGA, 2012, CAPONI, 2009), perceberemos que o entendimento e o condicionamento de sujeitos ao modelo de vida simples sofrem influências a partir de um pensamento medicalizante, na medida em que a intervenção nos corpos e na vida dos sujeitos que aderem a este estilo de vida é mediada, sobretudo, por um viés de pensamento e uma matriz biomédica.

É possível destacar, enquanto uma materialização hodierna dos processos referentes a este estilo de vida que privilegia a simplicidade, a revista Vida Simples, de publicação mensal da Editora Abril. Essa revista enfatiza temas relacionados aos aspectos que podem tornar a vida diária mais simples, descartando os excessos e os aspectos de consumo que medeiam 0 cotidiano dos grandes centros urbanos, apresentando informações a respeito dos benefícios das práticas corporais relacionando-as à saúde, assentadas e comprovadas, sobretudo, pelo discurso científico.

Segundo o próprio site da Editora Abril, a revista tem como objetivo levar "informações relevantes para o leitor que está em busca de uma rotina mais equilibrada", trazendo matérias sobre modos de morar, relações interpessoais, cultura e tendências (PUBLIABRIL, 2014). ${ }^{2}$ Os temas e reportagens que permeiam a revista Vida Simples foram analisados, neste artigo, a partir dos conceitos de medicalização (FOUCAULT, 1988, 1997b, GAUDENZI; ORTEGA, 2012, CAPONI, 2009) e de políticas da vitalidade, tal como referido por Rose (2013). Num

1 Quando nos referirmos ao termo vida simples, com letras minúsculas, estamos ressaltando a forma de viver sobre os preceitos de uma vida mais leve e minimalista, tal como apontado pela revista aqui analisada. Quando o termo Vida Simples constar nos nossos escritos com letras maiúsculas, estamos nos referindo à revista Vida Simples, das edições de 2014 quando pertencia à Editora Abril.

2 Em março de 2014, ao submetermos nosso projeto de pesquisa, utilizamos as informações fornecidas pelo site da Editora Abril, contudo, em junho de 2015, o site referenciado encontra-se indisponível, pois a revista Vida Simples passou a ser posse da Editora Caras, sendo apresentada aos leitores em sua nova página: http://vidasimples.uol.com.brl. A descrição da revista pela Editora Caras pode ser encontrada em sua mídia digital na página https://www.facebook.com/revistavidasimples/info/?tab=page info. 
mundo globalizado, em que se valora o conhecimento e a velocidade da informação, surgem questões relevantes para interpretação e identificação de temas cotidianos, os quais são trazidos, divulgados e difundidos por essa revista, tais como os benefícios à saúde através de práticas corporais alternativas.

Com vistas a uma delimitação teórico-conceitual inicial referente ao objeto central deste estudo, qual seja, as práticas corporais, indicamos a maneira pela qual as compreendemos e 0 modo como foi possível operar com esse termo nesta pesquisa. Ao analisarmos os diferentes processos de operacionalização das práticas corporais na revista Vida Simples pudemos depreender seu significado a partir de uma perspectiva calcada nas manifestações culturais. Entendemos que as práticas corporais estão imbuídas de expressões culturais diversas, desde aquelas referentes aos valores, sentidos e significados vinculados aos sujeitos que as praticam e produzem, como aos conteúdos presentes em suas manifestações (CARVALHO, 2006), podendo ser praticadas individualmente ou por diferentes grupos sociais "de forma institucionalizada, organizada e sistemática, mas também de forma espontânea, desestruturada e esporádica" (GONZÁLEZ, 2015, p. 136).

Cabe ressaltar que assunção da noção de práticas corporais ocorre "a partir das ciências humanas e sociais, das artes, da filosofia e dos saberes populares, sem desconsiderar as ciências biológicas e naturais" (WARSCHAUER et al., 2007, p. 3). O campo da Educação Física, segundo Lazzarotti Filho et al. (2010), pode ser considerado como aquele que usa o termo práticas corporais com maior frequência, especialmente a partir de estudos que fazem uso de perspectivas das Ciências Humanas, se referindo ao termo como uma série de atividades que não se restringem somente ao caráter biológico, tornando-o assim um conceito possível de operacionalização (LAZZAROTTI FILHO et al., 2010).

Além do mais, a discussão acerca das práticas corporais como medicalizantes tem sido alvo de investimentos teóricos e empíricos no campo da Educação Física. Gonçalves (2015) discutiu, por exemplo, os modos pelos quais os profissionais de Educação Física da cidade de Porto Alegre (RS), em seus distintos contextos de atuação, concebiam as práticas físicas e corporais que orientavam enquanto medicalizantes. Um dos desdobramentos de tal discussão se referiu à problematização da roupagem medicalizante que os exercícios físicos adquiriam quando prescritos aos usuários dos sistemas de saúde em que os profissionais investigados atuavam. Entrementes, na opinião desses profissionais, uma das formas de superar esse modelo biologicista estabelecido entre exercício físico e saúde com viés medicalizante era a proposição de práticas corporais (LAZZAROTTI FILHO et al., 2010). No entanto, é possível inferir, mesmo substituindo os exercícios físicos pelas práticas corporais, a superação da lógica medicalizante na qual as prescrições dos profissionais investigados se assentava não fora contemplada, na medida em que tanto os exercícios físicos como as práticas corporais eram propostos a partir de uma racionalidade biomédica, sendo este o registro preponderante no qual uma atividade pode ou não ser considerada medicalizante. De todo modo, este apontamento tem o intuito de tensionar os modos pelos quais as práticas corporais têm sido pensadas como alternativas às questões das atividades físicas ou dos exercícios físicos - estes tradicionalmente inseridos no rol da medicalização -, e o quanto tal substituição - dos exercícios físicos pelas práticas corporais - torna-se apenas uma retórica se não discutida no âmbito maior das racionalidades que sustentam estas ações ${ }^{3}$.

3 Cabe ressaltar que uma série de esforços teóricos e empíricos têm sido feitos em prol de uma discussão que promova uma reflexão e mudanças acerca das relações entre práticas corporais e saúde, especialmente na Educação Física (FRAGA; CARVALHO; GOMES, 2013, 
As atividades citadas pela revista aqui analisada seguem na direção de abordar elementos que não se restringem somente à lógica da atividade física como promotora de saúde pelo viés do gasto energético, indo além desse paradigma biologicista na medida em que envolvem aspectos de ordem social e cultural quando descrevem as práticas propostas. Desse modo, as atividades presentes na Vida Simples, na maior parte das vezes, destacam elementos referentes aos aspectos sociais intrínsecos a estas práticas, corroborando o que argumentam Silva e Damiani (2005) ao referir as práticas corporais como promotoras do cuidado de si e de uma maior sociabilização. Exemplos como a prática do tango enquanto "ferramenta terapêutica com efeitos curativos que favorece o sentimento de pertença ao grupo" (SAIBA..., 2014, p. 15), ou ainda, o depoimento de um ciclista sobre a importância de uma parceria "para dividir experiências" enquanto realizava uma volta ao mundo (RECORDAR..., 2014, p. 23) partilham das definições de práticas corporais aqui assumidas.

Nesse sentido, entendendo que a revista materializa temas culturais cotidianos é que foi possível analisá-la enquanto uma ferramenta atual para discussão de novas mudanças, especialmente àquelas relativas aos corpos e à vida. Desse modo, a partir das leituras realizadas e dos conceitos adotados para discussão, entendemos a necessidade de identificar e analisar as práticas corporais apresentadas, divulgadas e descritas pela e na revista Vida Simples nas edições de 2014, e compreender como o corpo transforma-se a partir de práticas que podemos definir como medicalizantes que, direta ou indiretamente, estão ligadas ao modo como nos tornamos sujeitos na atualidade. Os efeitos desses desdobramentos culturais são incontáveis, e vão desde um novo tipo de conhecimento sobre o ser humano e suas práticas corporais até atividades corriqueiras de nossas práticas de lazer, saúde e entretenimento.

Tomando tais apontamentos e fatos contemporâneos sobre práticas corporais, medicalização e políticas da vitalidade como ponto de partida, e contornando inicialmente esse tema a partir de algumas reflexões sobre o lugar das transformações do corpo na sociedade apresentados na revista Vida Simples, é que discutimos a seguir a metodologia empregada nesta investigação.

Esta investigação assenta-se no campo dos Estudos Culturais, sendo uma pesquisa documental com base na revista Vida Simples nas edições de 2014. Como destaca Corazza (2002, p. 355), as investigações realizadas neste campo de estudos empregam análises "pragmáticas, estratégicas e auto-reflexivas", na medida em que se propõem a analisar diversos domínios no âmbito da cultura. As práticas corporais apresentadas pela revista Vida Simples foram analisadas a partir da noção de medicalização dos corpos e políticas da vitalidade. Tomaram-se as revistas enquanto artefatos culturais, ou seja, enquanto documentos de uma determinada cultura que materializa sentidos e significados pertinentes à sociedade na qual está inserida, veiculando modos específicos de compreensão do mundo (ANDRADE, 2002).

O corpus de análise compõe-se das edições veiculadas ao longo do ano de 2014. Há que se ressaltar que a revista Vida Simples trabalha com publicações mensais, mas há algumas exceções em que ela traz duas edições no mesmo mês. As edições seguem a

GOMES; FRAGA; CARVALHO, 2015). No entanto, ressaltamos que, embora as práticas corporais se assentem em perspectivas voltadas às manifestações sociais e culturais dos indivíduos e comunidades, alicerçadas, sobretudo, no campo das ciências humanas, a assunção e a prescrição dessas práticas em substituição ao modelo tradicional estabelecido de atividades físicas ou exercícios físicos e saúde acabam sendo mera retórica, pois a finalidade de sua prescrição e, portanto, a razão que sustenta tal prescrição, está calcada na mesma racionalidade que prescreve as atividades físicas e exercícios físicos em prol da saúde, a saber, uma racionalidade biomédica. Desse modo, a prescrição das práticas corporais como forma de substituição das atividades físicas no campo da saúde pode retirar sua potência operacional voltada 
seguinte estrutura e seções: capa; comer; compartilhe; compartilhe/gente incrivel; compartilhe/ transformação; compartilhe/um café com; experiência; manual; pensando bem. Alguns dados foram disponibilizados no site da Editora Abril, tendo como fonte o IVC - Instituto Verificador de Circulação em MAIO/2014, os quais mostram uma tiragem de 74.478 exemplares, totalizando em média 85.196 leitores (PUBLI ABRIL, 2014).

A revista traz e veicula aos leitores determinados tipos de representações e modelos de corpos e de saúde, sugerindo o alcance destes através das práticas corporais ali discriminadas. Porém, segundo a Publiabril (2014), a revista dá pistas, sugere caminhos de como descomplicar a vida, tornando-se uma parceira essencial do dia a dia simplificado, pois traz aos leitores matérias sobre modos de morar, de relacionar-se interpessoalmente, de desenvolver cultura e identificar tendências.

Foi na trilha desse caminho metodológico e das escolhas conceituais sobre esse objeto de estudo que as análises seguintes foram realizadas. A seguir apresentamos e discutimos dois eixos de análise, a saber, a) as práticas medicalizantes e b) as questões de vitalidade presentes da revista Vida Simples.

\section{PRÁTICAS CORPORAIS MEDICALIZANTES}

Atualmente é comum referir que as atividades físicas e até mesmo as práticas corporais melhoram e aprimoram a condição de vida e saúde dos indivíduos, na medida em que aperfeiçoam aspectos de sua qualidade de vida, sobretudo aqueles relacionados às aptidões físico-corpóreas (NAHAS, 2012). Juntamente com esses argumentos criou-se um novo campo de fomento para a população: a busca da consciência e de mais informações a respeito de cuidados com a saúde, que incluem maior movimentação corporal e mudanças nos hábitos de vida, a dita busca pelo estilo de vida ativo. No entanto, cabe ressaltar que tais recorrências também puseram em movimento uma discussão acerca dos efeitos dessas práticas no que se refere aos controles dos corpos e ações dos indivíduos, tendo como efeito a manipulação e regularização deles, vinculados aos processos de saúde-doença e de desenvolvimento de novos modelos médico-sanitaristas de cuidado com 0 corpo e a saúde (FRAGA, 2006, FRAGA; WACHS, 2007).

O corpo, assim, é instrumento de investimentos sociais de ordem e preceitos biomédicos, e também objeto de disputa através de modos de funcionamento econômico e político sobre ele, tomando forma no campo da medicina e se espalhando para as outras áreas sociais e, especialmente, da saúde. Este campo de funcionamento econômico e político sobre o corpo Foucault (1988, 1997a, 1997b) denomina somatocracia: formas, estratégias, ações de controle e regulação do corpo em prol da saúde. Desse modo, através das muitas transformações, o corpo passou a ser objeto de intervenção médica, esvaindo-se para outros domínios e campos de atividade que, a partir da linguagem biomédica, o expandiram e estenderam num campo especifico de domínio (FOUCAULT, 1988, 1997a, 1997b). Sabe-se que não há convergência entre os teóricos para a definição de uma noção unívoca que dê conta de todo esse processo de controle sobre o corpo em prol da saúde a partir de uma racionalidade biomédica, mas, de algum modo, podemos sugerir, junto com outros autores, o termo medicalização (FOUCAULT, 1988, 1997b; GAUDENZI; ORTEGA, 2012, CAPONI, 2009).

Mesmo que muitos teóricos discordem sobre o uso do termo medicalização, este conceito originou-se na década de 1960, e compreende-se por uma série de rotulações 
normativas que fazem com que seres de comportamentos destoantes e desviantes sejam reféns de uma apropriação, de uma linguagem e de uma racionalização biomédica. Essa linguagem e essa racionalização biomédica compreendem uma nova nosologia, em que padrões de "normalidade" científicos e biológicos tentam compreender, regular, descrever, discriminar, abarcar, cooptar, governar, subjetivar corpos e práticas de saúde, em prol de uma economia social, tornando assim legítima a intervenção médica neste grupo (FOUCAULT, 1988; 1997b, GAUDENZI; ORTEGA, 2012, CAPONI, 2009).

No caso da revista aqui analisada as práticas sugeridas parecem se inserir nesse rol de pensamento medicalizante. É possível destacar, como um exemplo desse processo, a sessão "um café com" da edição de novembro de 2014, que teve como entrevistado Ignácio Lavalle Cobo (criador do psicotango), intitulada "O tango como terapia". Em seus escritos é possível perceber processos de medicalização desta modalidade terapêutica na medida em que, para este pesquisador e psicólogo, a modalidade é "capaz de apaziguar problemas de saúde por meio da dança típica argentina" (SAIBA..., 2014, p. 15). O trabalho é realizado em oficinas, em hospitais, espaços públicos, ou em seu consultório em Buenos Aires, onde seu divã foi substituído por um salão de dança. Essa terapia é relacionada para aliviar os sintomas de diversas patologias e é tratada como uma novidade terapêutica, embora esta prática corporal - a dança - seja retratada há centenas de anos. Desse modo, a dança passa a adquirir significados vinculados à função de possíveis melhoras do corpo - fisiológico -, fazendo com que se perca a centralidade dos sentidos de ordem social e afetiva que circundam sua prática desde os primórdios.

Além do mais, um simples ato de correr, realizado pelo homem há milhares de anos, também assume uma roupagem medicalizante na revista, na medida em que é recomendado aos sujeitos estarem atentos aos modos mais eficazes de realizar essa atividade, com vistas a aprimoramentos biológicos do corpo, referenciados por calorias, frequência cardíaca, etc. A matéria "Correndo pela cidade" da edição de setembro de 2014, poderia retratar apenas a experiência e as sensações obtidas pela prática de correr nas ruas de um bairro de São Paulo pelo jornalista autor da reportagem, enfatizando, por exemplo, as questões culturais envolvidas em sua corrida, as sensações filiadas ao lazer, ou outros desdobramentos. No entanto, em sua fala, a sua prática assume uma explicação de caráter médico-sanitarista, na medida em que enfatiza somente variantes biológicos relacionados à saúde, tais como a quantidade de calorias gasta, as mecânicas corretas do movimento de corrida, o calçado mais adequado à prática, entre outros aspectos.

Nos casos supracitados, os problemas são "definidos nos termos médicos, descritos a partir da linguagem médica, entendidos com base na adoção de um registro médico, ou 'tratados' com uma intervenção médica" (CONRAD, 2007 apud SANTOS, 2014, p.13). Desse modo, a medicalização dos corpos e da vida não se dá apenas pelos médicos, embora seja possível destacar que o controle social por eles é mais bem exercido, pois têm um grande poder de autoridade legitimado historicamente pela sociedade, definindo comportamentos, seres e situações, a partir da lógica e da racionalidade biomédica. Desse modo, as orientações, prescrições e encaminhamentos que originalmente surgem no campo médico são estendidos a outros campos de saberes e áreas da saúde, inclusive transbordando as fronteiras disciplinares dessas ciências ou práticas científicas, materializando-se, inclusive, em campos não científicos, como 0 caso da revista aqui analisada. Essas orientações de ordem biomédica são passadas 
a inúmeras gerações através do fenômeno aqui denominado de medicalização, o qual amplia o campo e a função da medicina tradicional, estendendo-se também, por exemplo, ao campo da revista Vida Simples a partir das falas de diferentes especialistas.

Se antigamente os discursos e orientações eram restritos somente aos médicos, autoridades legitimadas pelo seu poder histórico sobre os corpos, podemos afirmar que atualmente outras autoridades também ganham espaço, seja no campo da saúde seja no campo das ditas terapias complementares. Tomando, por exemplo, as análises que realizamos ao longo das edições de 2014 da revista Vida Simples, é possível destacar uma série de experts em saúde: nutrólogos, osteopatas, psicólogos, educadores físicos, pesquisadores de setores da saúde em universidades, terapeutas, etc. Há de se levar em conta, também, autoridades que aparecem na revista mas não fazem parte da dita medicina tradicional, e que mesmo sendo incluídas em menor escala mantêm-se ora auxiliando a medicina tradicional, ora se pondo contra ela. Essas figuras que ganham pouca credibilidade e são postas em dúvida por não pertencerem ao campo da ciência e da saúde tradicional são mestres em yoga, meditação, ecologia, e outros campos não tradicionais da saúde.

Embora a discussão acerca do processo medicalizante da vida dos indivíduos possa ter ganhado mais espaço em meados do século passado, é possível indicar que na atualidade tal conceito tem sido empregado em inúmeras áreas de discussão. Ao relacionar as práticas medicalizantes no âmbito dos processos escolares, Santos (2014) refere-se à medicalização como os processos pelos quais problemas não médicos (de ordem social, cultural, política e econômica, por exemplo) são definidos e tratados como problemas médicos, constituindo novas patologias. Esses processos são entendidos comumente como doenças e distúrbios, o que, consequentemente, aumenta gradativamente o processo de medicalização,

[...] tal como o surgimento de 'novos' desvios da vida 'normal' e a consequente transformação de comportamentos antes tidos como imorais, pecaminosos ou criminosos (tratados a partir de medidas de controle social) em problemas médicos (alcoolismo, tabagismo, distúrbios mentais, disfunções sexuais, menopausa, abuso sexual, saúde sexual masculina, homossexualidade, transexualidade, entre outros) (SANTOS, 2014, p. 27).

Assim, tanto por um lado, em que é possível transformar comportamentos imorais em doenças, é também possível, por outro, prevenir doenças físicas ou comportamentos desviantes através de práticas medicalizantes, tais como aquelas sugeridas pela revista Vida Simples, ao tratar as práticas corporais como atividades benéficas ao ser humano, valendo-se, para isso, de linguagem biomédica, transformando-as, desse modo, em práticas medicalizantes.

Como exemplo é possível destacar, na edição de junho de 2014, a matéria intitulada "Terapia Flutuante", que retrata a experiência da flutuação em um tanque escuro, que impede estímulos sensoriais externos (à prova de som), preenchido com 700 litros de água (mantida na temperatura média do corpo humano $35,5^{\circ} \mathrm{C}$ ), com profundidade rasa de $25 \mathrm{~cm}$ e diluição de 350 quilos de sal medicinal para que as pessoas possam flutuar sem nenhum esforço, o que promete levar o indivíduo a altos níveis de relaxamento e bem-estar. Além de benefícios tais como o estado de descanso e relaxamento intenso, essa terapia promete a sensação de bemestar e fortalecimento do sistema imunológico através da liberação de endorfina no corpo, pois uma hora de imersão equivale a de quatro a seis horas de sono profundo, sendo recomendadas, no mínimo, três sessões iniciais. Nas palavras do pesquisador, essa "terapia ajuda a melhorar 
insônia, ansiedade, depressão, doenças cardíacas, estresse, alívio de traumas emocionais, alinhamento da coluna vertebral, entre outros benefícios", na medida em que o relaxamento promove uma série de alterações de ordem fisiológica (AGRADECER..., 2014, p. 16).

A partir do princípio de que a medicalização pode ser compreendida como a atividade de considerar e tratar como problema de saúde e domínio médico algo que pode ser absolutamente normal e comum na vida de um ser humano, é possível depreender que tanto o psicotango, no caso já referido da psicoterapia que se vale desta dança, assim como a terapia flutuante, tal como recém referido, podem ser compreendidos como práticas cotidianas que se revestem de uma linguagem biomédica a fim de ganhar maior legitimidade em seus desenvolvimentos. Desse modo, quando a ciência médica se apropria da vida e dos corpos dos indivíduos, as experiências humanas se tornam passíveis de serem consideradas como problemas, desvios ou patologias, e desta forma acabam conformando modos homogeneizantes dos seres humanos localizarem a si e aos outros no mundo.

Este processo pelo qual o modo de vida dos homens é apropriado pela medicina interfere na construção de conceitos, regras de higiene, normas de moral, costumes prescritos (sexuais, alimentares, de habitação) e de comportamentos sociais. Assim, por sua vez, o corpo social sofre uma intervenção política (FOUCAULT, 1988, 1997b, GAUDENZI; ORTEGA, 2012, CAPONI, 2009). Problemas de diferentes ordens são apresentados como "doenças", "transtornos", "distúrbios" que escamoteiam as grandes questões políticas, sociais, culturais e afetivas que afligem a vida das pessoas, transformando questões não médicas em problemas médicos, e deste modo questões coletivas são tomadas como individuais, assim como problemas sociais e políticos são tomados como biológicos. Nesse ínterim, é possível enfatizar como exemplos do processo de medicalização da vida fatos tais como hiperatividade, dificuldades de aprendizagem, sono, infertilidade, alcoolismo, nascimento, morte, menopausa, comportamentos alimentares, reprodução, síndrome pré-menstrual, andropausa, disfunção eréctil, entre outros. E é nesse espaço político sobre o corpo que as práticas corporais e as terapias complementares acabam ocupando espaço na conquista de uma vida simples.

\section{POLÍTICAS DA VITALIDADE E AS “DESOTIMIZAÇÕES” DAS PRÁTICAS CORPORAIS}

Com os processos de transformação da sociedade nas últimas décadas, mediados pelos avanços científicos nas mais diversas áreas, em especial nas ciências voltadas às tecnologias sobre a vida, as concepções de ser e de mundo também foram alteradas. Hoje 0 pensamento e a existência humana perpassam por um caminho potencializado pelo científico, em que a tônica desse processo não reside apenas no fato de vivermos mais (tal como uma promessa tipicamente moderna), mas, sim, na tentativa de vivermos mais e melhor, numa incansável e incessante busca pela otimização máxima da saúde, da vida e do corpo (SUSIN; SANTOS, 2014, RIBEIRO, 2003, ROSE, 2013).

Rose (2013) refere que nesse escopo o processo medicalizante surtiu em nós um efeito ainda mais profundo, transformando e fazendo de nós aquilo que gostaríamos de ser de forma ainda mais latente. $\mathrm{O}$ autor reflete e discute acerca das políticas sobre a vida, e propõe uma atualização dos conceitos de biopoder e de biopolítica propostos nas obras de Foucault (1988; 1997b), argumentando que as políticas sobre a vida desenvolvidas nos séculos XVIII e XIX abordadas por Foucault se definiam muito mais enquanto políticas de saúde voltadas a 
compreender e regular as taxas e números de nascimentos e mortes, de doenças e epidemias, de saneamento e distribuição de águas, e outros fatores que compunham as capacidades vitais da população das grandes cidades europeias. Avançando na primeira metade do século $X X$, tais políticas ganharam impulsos de incremento da vida através do melhoramento da raça, do controle de periculosidades, do gerenciamento das famílias, da compreensão das características populacionais através de noções eminentemente biológicas.

No entanto, para Rose (2013), as políticas sobre a vida no século XXI operam em outros domínios, em diversos níveis, através de distintos processos daqueles referentes aos séculos XVIII, XIX e primeira metade do XX. As políticas de vida do século XXI buscam elementos, fatores, dados, taxas diferentes destas anteriores. Elas não são delimitadas "pelos polos de doença e saúde, nem focadas na eliminação das patologias para proteger o destino da nação", mas, sim, tais políticas são concebidas e recombinadas a partir do aumento de nossa capacidade para controlar, gerenciar, refazer e modular as distintas capacidades vitais que o ser humano pode vir a ter, tomando o ser humano enquanto criatura viva manipulável (ROSE, 2013, p. 3). Esses processos, capacidades, destrezas, estratégias, saberes e pulsão Rose (2013) denomina políticas da "própria vida". A história nos mostra que durante séculos a medicina buscou tratar o que considerava anormalidades. Porém, nos dias atuais, o que pode ser dito, chamado ou caracterizado de normal também está aberto a sofrer e transformar-se a partir de modificações biomédicas. Todo esse processo perpassa por uma nova compreensão molecular de corpos e de mentes, e de novas técnicas para manipulação de processos básicos da vida no nível molecular, celular e, sobretudo, genético. A política da própria vida oferece uma análise indispensável dos desenvolvimentos recentes nas ciências da vida e na biomedicina, que têm levado à difusa politização da medicina, da vida humana e da biotecnologia. Evitando o exagero da ciência popular e do pessimismo da maioria das ciências sociais, Rose (2013) analisa a biopolítica molecular contemporânea examinando desenvolvimentos em torno do genoma, da neurociência, da farmacologia e da psicofarmacologia, e os modos pelos quais têm afetado a política racial, o controle do crime e a psiquiatria. Rose (2013) ainda analisa a transformação da biomedicina a partir da prática de curar e potencializar a própria vida enquanto ferramenta de seu próprio governo.

No que se refere à revista aqui analisada, é possível destacar que, por um lado, tal como já referido, ela opera na lógica da medicalização das práticas corporais apresentadas. No entanto, em contrapartida, no que se refere às políticas da vitalidade destacadas por Rose (2013), poderíamos refletir se a revista Vida Simples apresenta um processo, se não contraditório, ao menos mais distante das políticas da vitalidade. Isto porque enquanto o processo discutido por Rose (2013) evidencia a condição humana num escopo de viver mais e viver melhor, como a busca incessante pelo "plus" ou pelo "algo mais" para otimizar a vida e o corpo, de fato potencializando-o, algumas das matérias da revista tematizam justamente o contrário, enfatizando a busca pela neutralidade da vida, pelo minimalista, por um estado "zero", incluindo aqui a decisão de viver de forma realmente simples e, diríamos até mesmo, em termos de "negativação" da "positivação" da otimização da vida. No entanto, é possível indagar se tal "negativação" não estaria, por outro lado, procurando justamente ampliar certa "positivação" da vida, indo na direção, nesse caso, de uma otimização através de processos minimalistas.

Tomemos, por exemplo, a publicação de julho de 2014 da revista, que remete a meditação, ou ainda, a edição de setembro, que traz uma reportagem sobre ecologia médica, e 
até mesmo a publicação de janeiro do referido ano, acerca dos ensinamentos de uma nutróloga sobre os processos de alimentação. Ambos os casos referem-se a uma forma de viver que descarta as características da vida exaltada e potencializada, embora apresentem, também em comum, as características que levam as pessoas a procurarem por estas atividades, a saber, uma melhor qualidade de vida, ou um modo de prolongar a vida dando maior qualidade ao processo vital. Porém, este prolongamento da vida, ou melhora da qualidade de vida, não se assenta em preceitos de gerenciamento a partir de otimizações do corpo, mas, sim, enfatiza apenas o equilíbrio da vida, como uma espécie de busca da homeostase. Mesmo que tal equilíbrio não se assente diretamente numa otimização do corpo, mas, sim, numa diminuição das capacidades de otimização do corpo, em prol de uma espécie de economia vital, este pode estar, por outro lado, na direção de um incremento da vida, na medida em que a desaceleração do corpo pode implicar uma melhora vital.

Em julho, a reportagem intitulada "A primeira meditação" retrata momentos importantes ao observar o fluxo de pensamentos e autodescoberta. A aula retratada na reportagem foi ministrada gratuitamente por um servidor público que pratica meditação há mais de dez anos, e sua prática, segundo ele, pode trazer paz e conhecimento, facilitando uma harmonização e sintonia com o ambiente e consigo (PENSE..., 2014, p. 16). Já a reportagem "Aula de comer", desta mesma edição, retrata a ida de um repórter a uma clínica de medicina complementar, onde elementos da medicina tradicional são combinados com práticas de homeopatia, acupuntura, nutrologia e medicina comportamental. Essa terapia proporciona ao indivíduo uma maior consciência alimentar para melhora do funcionamento do corpo, sono e disposição (PENSE..., 2014).

Por outro lado, a matéria acerca da ecologia médica afirma que essa terapia pode ajudar os visitantes a entrar em sintonia com o ambiente e consigo mesmos. O médico homeopata pesquisou "maneiras de ajudar as pessoas a compreenderem as mensagens por trás das doenças" e "adaptou um modelo desenvolvido pelo físico quântico Amit Goswani, que propõe tratar o ser humano em suas cinco dimensões: física, metabólica, vital, mental e supramental (espiritual)" (PENSE..., 2014, p. 12). O propósito dessa terapia é encontrar meios próprios para reconectar-se à própria essência, descobrindo seu propósito de vida. Tal terapia tem como finalidade gerar saúde a si mesmo a partir da fauna e flora variada encontrada no Centro de Ecologia Médica Florescer da Mata, através de oficinas sobre meditação, sonhos, terapia com animais, alimentos vitalizados, e ervas medicinais, com uma equipe transdisciplinar formada por diversos profissionais, como nutrólogos, médicos, nutricionistas, psicólogos e fisioterapeutas.

Para finalizar, gostaríamos de trazer a reportagem "O amante do mar". Nessa reportagem Henrique Pistilli, que é consultor, palestrante, professor, atleta e praticante de polo aquático e surf de peito retrata e analisa sua vida. Pistilli afirma que sua vida está fortemente ligada a atentar para o "inconsciente, para nossas vísceras, nosso querer e para a fala do coração" (PENSE..., 2014, p. 46), estreitando estas relações a partir de uma ligação profunda com o mar.

Pistilli critica as condições atuais em que vivemos nos grandes centros urbanos, destacando que na atualidade "tudo tem que ter uma meta, um resultado, um retorno, e que vivemos em busca da perfeição". Segue o entrevistado relatando: "aprendi com o mar que, às vezes, o melhor é não ter meta e que a imperfeição faz parte da vida" (PENSE..., 2014, p. 47). Essa afirmação vai de encontro ao que é preconizado pela política da vitalidade, na medida em que esta justamente compreende a perfeição não apenas como algo alcançável, mas 
principalmente moldável e desejável no mundo hodierno. No entanto, não buscar a perfeição pode não estar relacionado diretamente a um afastamento total da vitalidade, na medida em que, para o entrevistado, é justamente nessa frenagem na busca da perfeição que é possível alcançar uma vida melhor.

Parece-nos que os excertos aqui analisados expõem uma espécie de descompasso com as políticas da vitalidade desenvolvidas por Rose (2013), na medida em que a política da vitalidade atinge um campo voltado à potencialização da vida e a revista Vida Simples, através de suas reportagens acerca das práticas corporais, foca em questões de ordem mais minimalistas e simplificadoras de viver a vida, talvez a "despotencializando", ou ainda, a "desotimizando". Por outro lado, mesmo que as práticas propostas pareçam atuar numa "desotimização" do corpo e das capacidades corporais, estas podem, por sua vez, atuar numa otimização da vida, na medida em que a melhoram. Reside aqui, para nós, um paradoxo contemporâneo, em que a diminuição da otimização corporal pode, paralelamente, otimizar a vida, desde os preceitos minimalistas apontados pela revista.

\section{A SIMPLES VIDA SIMPLES}

As práticas corporais presentes nas reportagens publicadas na revista Vida Simples durante 0 ano de 2014 foram descritas e sugeridas aos leitores valendo-se de argumentos de ordem biomédica, tornando-as, em boa parte das vezes, práticas medicalizantes e medicalizadas. Não temos dúvidas de que as práticas corporais e terapias complementares modificaram-se ao longo dos anos, e ainda passarão por inúmeras modificações. As novas tecnologias disponíveis, bem como as autoridades que as promulgam e os locais em que são praticadas, valem-se de argumentos científicos para descrever seus benefícios.

Entendemos que no cenário atual os professores e profissionais de Educação Física são as figuras mais adequadas para promulgar a recomendação de atividades físicas e corporais tidas como saudáveis e benéficas, porém, nesse ínterim, outras profissões da saúde também têm se valido dos aspectos científicos das descobertas biotecnológicas para prescreverem atividades inseridas em suas especialidades. Nesse movimento parece haver uma transformação e ampliação de práticas corporais antes tidas como culturais ou "naturais" pela sociedade para um tipo de prática que passa a ocupar um lugar num contexto de ordem biomédica, patologizante e de matriz biológica. Assim, há a necessidade de identificar e analisar as "novas, antigas e repaginadas" práticas corporais apresentadas, divulgadas e descritas pela e na revista Vida Simples, bem como em outras publicações que alcancem um grande número de leitores, a fim de compreendermos como o corpo transforma-se a partir de práticas corporais medicalizantes que, direta ou indiretamente, estão ligadas ao modo como nos tornamos sujeitos na atualidade. No entanto, quanto às questões de otimização dos corpos, percebemos que as reportagens desenvolvidas não apresentaram argumentos substanciais para que possamos rotular tais práticas como inseridas num cenário de aumento de vitalidade, ou ainda, de otimização dos corpos, tal como sugerido por Rose (2013), embora tais questionamentos possam se manter abertos na direção de uma problematização dessas práticas a partir desse conceito. Pelo contrário, o que foi destacado é o fato da busca por saúde através de um viés que alcance os preceitos minimalistas da vida. Desse modo, deixamos em aberto uma reflexão sobre as práticas corporais apontadas 
pela revista, na medida em que podem, em muitos momentos, ser problematizadas na direção de uma otimização da vida não somente por um viés de potencialização, mas de melhora qualitativa de seus aspectos.

Ressaltamos que as práticas corporais e terapias complementares deverão transformar-se no decorrer dos anos seguintes, alastrando-se no tecido social, especialmente se mediadas pelas intervenções das descobertas das tecnologias sobre a vida. Isto indica a necessidade de um retorno constante e permanente a análises acerca dos modos pelos quais as práticas corporais são desenhadas nos diversos cenários culturais em que estamos inseridos, sendo, portanto, fundamental a realização de outros estudos a partir desse tema, a fim de compreender como aquilo que nos é incitado a fazer se transforma a partir de novos campos de conhecimento.

\section{REFERÊNCIAS}

ACIDENTES acontecem. Vida Simples, São Paulo, n. 144, maio 2014.

ACREDITE nos seus sonhos. Vida Simples, São Paulo, n. 153, dez. 2014.

AGRADECER faz bem. Vida Simples, São Paulo, n. 145, jun. 2014.

ANDRADE, Sandra dos Santos. Uma boa forma de ser feliz: representações de corpo feminino na revista Boa Forma. Dissertação (Mestrado) - Faculdade de Educação, Universidade Federal do Rio Grande do Sul, Porto Alegre, 2002.

BRASIL. Ministério da Saúde. Secretaria de Atenção à Saúde. Departamento de Atenção Básica. Política Nacional de Práticas Integrativas e Complementares no SUS - PNPIC-SUS. Brasília: Ministério da Saúde, 2006. Disponível em: <http://dab.saude.gov.br/portaldab/pnpic.php >. Acesso em: 27 mar. 2013.

CAPONI, Sandra. Biopolítica e medicalização dos anormais. Physis: revista de saúde coletiva. Rio de Janeiro, v. 19, n. 2, 2009, p.529-549.

CARVALHO, Yara Maria de. Promoção da saúde, práticas corporais e atenção básica. Revista Brasileira de Saúde da Família, Brasília: Ministério da Saúde, v. VIII, p. 33-45, 2006.

CHORAR é bom. Vida Simples, São Paulo, n. 148, ago. 2014.

COMEÇAR de novo. Vida Simples, São Paulo, n. 142, mar. 2014.

CORAZZA, Sandra Mara. Manual infame... mas útil para escrever uma boa proposta de tese ou dissertação. In: BIANCHETTI, Lucídio; MACHADO NETO, Ana. Maria. (Org.). A bússola do escrever: desafios e estratégias na orientação de teses e dissertações. Florianópolis: Ed. da UFSC, 2002, p. 355-370.

ERRAR faz parte. Vida Simples, São Paulo, n. 141, fev. 2014.

FAÇA o seu caminho. Vida Simples, São Paulo, n. 150, set. 2014.

FOUCALT, Michel. Crise da medicina ou crise da antimedicina. In: Verve, São Paulo, n. 18, 2010, p.167-194.

FOUCALT, Michel. História da sexualidade. In: FOUCALT, Michel. Resumo dos cursos do Collège de France (1970 - 1982). Tradução de Andréa Daher. Rio de Janeiro: Jorge Zahar Ed., 1988, p.125-149.

FOUCALT, Michel. É preciso defender a sociedade. In: FOUCALT, Michel. Resumo dos cursos do Collège de France (1970 - 1982). Tradução de Andréa Daher; consultoria, Roberto Machado. Rio de Janeiro: Jorge Zahar Ed., 1997a, p. 69-78. 
FOUCALT, Michel. Nascimento da biopolítica. In: FOUCALT, Michel. Resumo dos cursos do Collège de France(1970 - 1982). Tradução de Maria Tereza da Costa Albuquerque. Rio de Janeiro: Jorge Zahar, 1997b, p. 87-98.

FRAGA, Alex Braga; CARVALHO, Yara Maria; GOMES, Ivan Marcelo. (Org.). As práticas corporais no campo da saúde. São Paulo, Hucitec, 2013.

FRAGA, Alex Braga; WACHS, Felipe. Educação Física e saúde coletiva: políticas de formação e perspectivas de intervenção. 2. ed. Porto Alegre: Editora da UFRGS, 2007.

FRAGA, Alex Branco. Exercício da informação: governo dos corpos no mercado da vida ativa. Campinas, SP: Autores Associados, 2006.

GAUDENZI, Paula; ORTEGA, Francisco. O estatuto de medicalização e as interpretações de Ivan Illich e Michel Foucault como ferramentas conceituais para o estudo da desmedicalização. Interface, Botucatu, v. 16, n. 40, p. 21-34, jan./mar. 2012.

GOMES, Ivan Marcelo; FRAGA, Alex Braga; CARVALHO, Yara Maria. (Org.).

Práticas corporais no campo da saúde: uma política em formação. Porto

Alegre: Rede UNIDA, 2015. Disponível em: <https://www.google.com.br/?gws rd=ssl\#q=Pr\%C3\%A1ticas+corporais+no+campo+da+sa\%C3\%BAde>. Acesso em: 01 agosto 2015.

GONÇALVES, Alana Martins. A inserção de profissionais de educação física em ambientes de saúde. Tese (Doutorado em Educação em Ciências) - Programa de Pós-Graduação em Educação em Ciências: Química da Vida e Saúde, Universidade Federal do Rio Grande do Sul, Porto Alegre, 2015.

GONZÁLEZ, Fernando Jaime. Práticas corporais e o sistema único de saúde: desafios para a intervenção profissional. In: GOMES, Ivan Marcelo; FRAGA, Alex Braga; CARVALHO, Yara Maria (Org.). Práticas corporais no campo da saúde: uma política em formação. Porto Alegre: Rede UNIDA, 2015. p. 135-162.

LAZZAROTTI FILHO, Ari et al. O termo práticas corporais na literatura científica brasileira e sua repercussão no campo da Educação Física. Movimento, Porto Alegre, v. 16, n. 1, p. 11-29, jan./mar. 2010.

LIBERTE-SE da rotina. Vida Simples, São Paulo, n. 149, set. 2014.

NAHAS, Markus Vinicius. Atividade física, saúde e qualidade de vida: conceitos e sugestões para um estilo de vida ativo. 5. ed. rev. atual. Londrina: Midiograf, 2010.

OUÇA o silêncio. Vida Simples, São Paulo, n. 140, jan. 2014.

PENSE com seus botões. Vida Simples, São Paulo, n. 147, jul. 2014.

PUBLIABRIL, Editora Abril S.A. Disponível em: <http://www.publiabril.com.br/marcas/vidasimples/ revista/informacoes-gerais>. Acesso em: 27 de março de 2013.

RECORDAR é viver. Vida Simples, São Paulo, n. 146, jun. 2014.

RIBEIRO, Renato Janine. Novas fronteiras entre natureza e cultura. In: NOVAES, Adauto. (Org.). 0 homem-máquina: a ciência manipula o corpo. São Paulo, Companhia das Letras, 2003. p. 15-36.

ROSE, Nikolas. A política da própria vida: biomedicina, poder e subjetividade no século XXI. Tradução de Paulo Ferreira Valerio. São Paulo: Paulus, 2013.

SAIBA conversar. Vida Simples, São Paulo, n. 152, nov. 2014.

SANTOS, Luís Henrique Sacchi dos. Escola, currículo e medicalização do corpo. In: SANTOS, Luís Henrique Sacchi dos; SUSIN, Loredana; DARSIE, Camilo; ZAGO, Luiz Felipe (Org.). Formação de professores em um mundo em transformação. Santa Cruz do Sul: Ed. EDUNISC, 2014. p. 26-38.

SEJA mais doce. Vida Simples, São Paulo, n. 151, out. 2014. 
SILVA, Ana Márcia; DAMIANI, lara Regina. As práticas corporais na contemporaneidade: pressupostos de um campo de pesquisa e intervenção social. In: SILVA, Ana Márcia; DAMIANI, lara Regina. (Org.). Práticas corporais. Florianópolis: Nauemblu Ciência \& Arte, 2005. v. 1: Gênese de um movimento investigativo em Educação Física.

SOLTE a imaginação. Vida Simples, São Paulo, n. 143, abril, 2014.

WARSCHAUER, Marcos et al. As escolhas das práticas corporais e dos profissionais que conduzem as práticas nas Unidades Básicas de Saúde do distrito Butantã-SP. In: CONGRESSO BRASILEIRO DE CIÊNCIAS DO ESPORTE, 15., 2007, Recife. [Anais...]. p. 27. Disponível em: <http//:www.cbce. org.br/resumos/003.pdf>. Acesso em: 1‥ ago. 2015. 